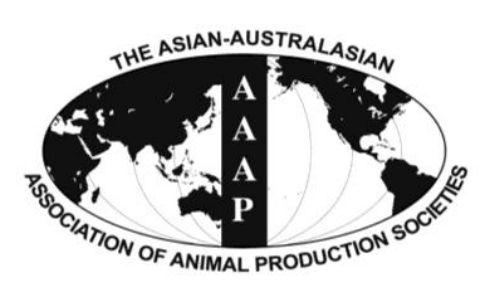

\title{
Effect of Various Phyto-extracts on Physico-chemical, Colour, and Oxidative Stability of Pork Frankfurters
}

\author{
Rajesh V. Wagh, Manish K. Chatli ${ }^{1} *$, Marita Ruusunen, Eero Puolanne, and Per Ertbjerg \\ Department of Food and Environmental Sciences, University of Helsinki, Helsinki 00014, Finland
}

\begin{abstract}
Lipid oxidation, colour stability and physico-chemical quality of pork frankfurters with the incorporation of $0.30 \%$ sea buckthorn (SBT), $0.10 \%$ grape seed (GSE), $0.03 \%$ green tea (GTE), $0.12 \%$ fenugreek seed (FSE) and $0.10 \%$ Acacia catechu (ACE) were studied during 20 days of refrigerated aerobic storage. The SBT and ACE were identified as being the most effective antioxidants to retard lipid oxidation with the potency decreasing in the following order: SBT $>$ ACE $>$ GSE $>$ GTE $>$ FSE based on thiobarbituric acid reacting substances, peroxide value and free fatty acids. In all samples $\mathrm{pH}$ and $\mathrm{a}_{\mathrm{w}}$ decreased during storage period. The $L^{*}$ value of treated as well as control samples decreased over time while SBT and ACE exhibited an increased redness producing higher $a *$ values than other treatments. However, GTE was more effective in increasing $b^{*}$ values than other treatments at the end of storage. The results suggest that functional plant-derived extracts can be valuable to the modification of frankfurter formulations for improved oxidative stability as well as quality characteristics. (Key Words: Sea Buckthorn Seed, Acacia catechu, Grape Seed, Green Tea, Fenugreek Seed, Lipid Oxidation, Pork Frankfurters)
\end{abstract}

\section{INTRODUCTION}

Lipid peroxidation, the oxidative deterioration of the polyunsaturated lipids of food, leads through formation of hydroperoxides to short-chain aldehydes, ketones, and other oxidised compounds, which are considered to be responsible for causing flavour, texture, colour and nutritional deterioration of meat and meat products. Several adverse health effects, due to the presence of free reactive oxygen species (ROS), such as superoxide radical, hydroxyl radical, peroxyl radical, during lipid oxidation, have been reported (Nissen et al., 2004). Therefore, to avoid or delay the lipid oxidation processes in meat, meat product manufacturers have used several synthetic food additives in the past few decades such as nitrites, butylated hydroxytoluene and butylated hydroxyanisole (Mc Carthy

\footnotetext{
* Corresponding Author: Manish K. Chatli. Tel: +91-161-241 4025, Fax: +91-161-2400822, E-mail: manishchatlilpt@gmail.com

${ }^{1}$ Department of Livestock Products Technology, College of Veterinary Science, Guru Angad Dev Veterinary and Animal Sciences University, Punjab, Ludhiana 141 004, India.

Submitted Sept. 16, 2014; Revised Dec. 17, 2014; Accepted Jan. 19, 2015
}

et al., 2001). But currently research for new bio-efficient antioxidants has particularly focused on natural antioxidants to respect the consumer concerns over safety and toxicity problems caused by synthetic antioxidants (Armenteros et al., 2013). Natural antioxidants are primarily plant phenolic that may occur in all parts of plants, such as fruits, nuts, seeds, leaves, roots and barks (Salejda et al., 2011). In the recent years many studies have been evaluating these natural substances as antioxidative additives in meat products leading to the development of novel food products (Devatkal et al., 2012) and their effectiveness in extending shelf-life of the products has been widely documented (Kumar et al., 2013).

Hippophaë rhamnoides L. (Elaeagnaceae), commonly known as sea buckthorn (SBT), which is an Eurasian nitrogen-fixing actinomycetes naturally distributed in Asia, Europe and also introduced in North and South America (Bal et al., 2011). Sea buckthorn are among the most nutritious and vitamin-rich berries found in the plant kingdom ( $\mathrm{Li}$ and Schroeder, 1996). The berries contain more than 100 different kinds of nutrients like carbohydrates, protein and fat soluble vitamins, 
antioxidants (i.e. vitamins $\mathrm{C}$ and $\mathrm{E}, \quad \beta$-carotene, and lycopene), essential fatty acids, amino acids, phytosterols, and potent antioxidant quercetin, as well as other flavonols in various glycosidic forms in addition to chemical elements (i.e. iron, calcium, etc.) which contribute to health benefits including anti-inflammatory, antimicrobial, analgesic, promotion of tissue regeneration, immunomodulatory and protection against cancer and cardiovascular disease (Michel et al., 2012).

Some in-vitro studies in raw beef, pork, chicken (Papuc et al., 2009) demonstrated that SBT polyphenols have ability to scavenge ROS and retard lipid per-oxidation process in meat systems; however, the literature is almost silent for the utilization/inclusion of SBT bioactive ingredients in processed meat products.

Grape seed extract (GSE) is a by-product derived from the grape seeds (Vitis vinifera) that is extracted, dried and purified to produce an extract rich in polyphenolic compounds (Lau and King, 2003). There are increasing evidence demonstrating the ability of GSE to retard lipid oxidation in meat and meat products during storage, most likely due to the fact that GSE is a rich source of monomeric phenolic compounds, such as catechin, epicatechin and especially proanthocyanidins (Ozvural and Vural, 2011). In raw and cooked meat products, GSE has been shown to be effective in reducing the amount of primary lipid oxidation products (e.g. lipid hydroperoxides and hexanal) and secondary lipid oxidation products (e.g. thiobarbituric acid reactive substances) in cooked meat products like pork patties (Nissen et al., 2004).

Green tea extract (GTE) is a derivative of cultivated evergreen tea plant (Camellia sinensis L.) of the family Theaceae, concentrated to solids $(40 \%$ to $50 \%)$. It consists of catechin gallate, gallocatechin gallate, epicatechin gallate, caffeine, proanthocyanidins, and flavonols which endows its role as antioxidant, antimicrobial, anti-carcinogenic, and anti-arteriosclerotic agent. The strong free-radicalscavenging ability plus the iron-chelating effect of tea catechins polyphenols provide a plausible mechanism for the antioxidant effects in various meat systems (Salejda et al., 2011).

Fenugreek, Trigonella foenum-graecum L., is an annual legume crop mainly cultivated for use as a spice in many parts of the world. Fenugreek exert as digestive stimulant, cholesterol-lowering, gastroprotective, hepatoprotective, antidiabetic and a potent antioxidant, which direct it's promising application for the development of healthier meat and meat products (Devatkal et al., 2012).

Acacia catechu, commonly known as catechu, is an important medicinal plant, especially prevalent in Asia. A wide spectrum of compounds that have been isolated and characterized mostly from bark of A. catechu include 4hydroxybenzoic acid, kaempferol, quercetin, catechin, rutin, isorhamnetin and epicatechin (Li et al., 2011). It exhibits strong antioxidant, astringent, anti-inflammatory, antifungal and a potential anti-HIV agent in nature (Nutan et al., 2013) In spite of such novel properties, the utilization of Acacia catechu into meat system is almost unexplored.

Frankfurters are non-fermented, emulsion-type popular meat product widely marketed and consumed in the world. However, they have shorter shelf life due to proneness to oxidation as release of haem iron during mincing, cooking and the addition of salt, promotes the formation of ROS, leading to increase in the development of oxidative reactions during storage (Armenteros et al., 2013).

The present study was conducted to elucidate the effect of SBT, GSE, GTE, FSE, and ACE during storage of pork frankfurters in relation to lipid oxidation, physicochemical and colour stability. The emphasis was also given to compare the antioxidant potential of the extracts.

\section{MATERIALS AND METHODS}

\section{Chemicals}

All chemicals used were 'AnalaR' grade and were obtained from Sigma Chemical Co., Ltd, Poole, Dorset, UK; Rathburn Chemical Co., Ltd, Walkerburn, Peebleshire, Scotland; and Merck, Darmstadt, Germany. Water used throughout the work was purified through the Milli-Q equipment (Millipore Corp., Bedford, MA, USA). The sources of the phyto-extracts ingredients/antioxidants used were as follows: GSE, GTE, FSE, and ACEs were procured from a food supplements company (Ambe Phytoextracts Pvt. Ltd. An ISO 9000:2000 company, New Delhi, India).

\section{Preparation of sea buckthorn extracts}

Sea buckthorn berries were collected from the NorthWestern Himalayan region (Himachal Pradesh, India) and seeds were obtained after deseeding the berries by passing through stainless steel sieve and dried in a cabinet dryer. Dried seeds were powdered into a particle size of 60 to 80 mesh and successively extracted. Ten grams of the powder were weighed and mixed with $100 \mathrm{~mL}$ of $60 \%$ aqueous methanol extracting solvent in a conical flask. The mixture was shaken at constant rate of $300 \mathrm{rpm}$ using a shaker (Sartorius, CERTOMAT-MO II, Gottingen, Germany) for overnight. The obtained extracts were filtered through a Whatman filter paper No. 1 in order to obtain a particle free extract and evaporated using a rotary evaporator (Büchi Labortechnik AG, Flawil, Switzerland) under vacuum at $45^{\circ} \mathrm{C}$ to $55^{\circ} \mathrm{C}$ and a rotation speed of $100 \mathrm{rpm}$ for a period of 20 to $25 \mathrm{~min}$. The resultant clear solution was collected in an amber reagent bottle. The extract was stored at $-20^{\circ} \mathrm{C}$ for further studies. The methanolic extract of Hippophae rhamnoides referred hereafter as SBT. Before the manufacture of the frankfurters, methanol was completely 
removed from SBT in a rotary evaporator (Büchi Labortechnik AG, Flawil, Switzerland) until methanol condensation on the cooling coil of the evaporator was no longer observed.

\section{Preparation of frankfurters}

The frankfurters were manufactured in the University of Helsinki meat pilot plant. The control frankfurters were prepared from $64 \%$ pork shoulder (11\% fat, $19 \%$ protein), $10 \%$ pork back fat ( $88 \%$ fat), $5 \%$ pork skin ( $25 \%$ fat) and $15 \%$ ice. Additional ingredients ( $\%$ of meat/fat/ice mixture) were as follows: $1.6 \%$ salt, $1 \%$ soya isolate, $0.4 \%$ dextrose, $0.40 \%$ phosphate, $0.07 \%$ ascorbate, $0.01 \%$ sodium nitrite, $0.08 \%$ black pepper, $0.11 \%$ white pepper, $0.15 \%$ sweet paprika, $2 \%$ condiments mix. Six different treatments of frankfurters were developed viz. Control (without phytoextracts), SBT $(0.30 \%)$, GSE $(0.10 \%)$, GTE $(0.03 \%)$, FSE $(0.12 \%)$, and ACE $(0.10 \%)$. The levels of incorporation of selected phyto-extracts were determined by conducting preliminary trials in the department. The meat/fat mixture was chopped for 20 to $30 \mathrm{~s}$ in a cutter (Meat Chopper, Seydelmann Maschinenfabrik Seydelmann KG, Stuttgart, Germany) at low speed (100 rpm) and mixed with the curing ingredients, seasonings and about half of the ice. The mixture was chopped for 2 to $3 \mathrm{~min}$ and the remaining ice and fat were added. After $3 \mathrm{~min}$, chopping was performed at maximum speed $(5,500 \mathrm{rpm})$ until the desired emulsion viscosity was obtained. The temperature of the mixture was not allowed to exceed $12^{\circ} \mathrm{C}$. After chopping, the batters were stuffed into sheep casings (diameter 21 to $23 \mathrm{~mm}$ ) and linked at 18 to $20 \mathrm{~cm}$ intervals using vacuum sausage filler (Handmann VF50, Albert Handtmann Maschinenfabrik GmbH \& Co. KG, Stuttgart, Germany). Frankfurters were heat processed in a smokechamber (Vemag Aeromat Smokehouse, VEMAG Maschinenbau GmbH, Verden, Germany) until the core temperature reached $70^{\circ} \mathrm{C}$. The frankfurters were then showered with cold water for $5 \mathrm{~min}$, removed from the smokechamber and chilled at $0^{\circ} \mathrm{C}$. After chilling, the frankfurters were aerobically packed in low density polyethylene bags and stored in dark at the refrigeration temperature of $4 \pm 1^{\circ} \mathrm{C}$. The samples were drawn on 1st, 5th, 10th, 15th, and 20th day of storage for evaluation of thiobarbituric acid reacting substances (TBARS) values, $\mathrm{pH}$, water activity $\left(\mathrm{a}_{\mathrm{w}}\right)$, peroxide value (PV), free fatty acids (FFA) and instrumental colour characteristics.

\section{Water activity and pH measurement}

The $\mathrm{pH}$ values of the frankfurters were measured directly with a Xerolyte electrode (Ingold Xerolyt LoT406M6, Inlab 427, Mettler Toledo GmbH, Giessen, Germany). The water activity of the samples was measured using an
Aqua Lab water activity meter (Series 3TE, Stockholm, Sweden) following the manufacturer's instructions.

\section{Instrumental colour profile}

Colour measurements were taken on the inner surface of vertically cut pork frankfurters immediately (in order to prevent colour degradation due to light and oxygen) after opening the package. The following colour coordinates were determined: lightness $\left(L^{*}\right)$, redness $\left(a^{*}\right)$, and yellowness $\left(b^{*}\right)$. The colour parameters were determined using a Minolta Chroma meter CR-400 (Minolta Camera Co., Osaka, Japan) (Illuminant D65/0 ${ }^{\circ}$ standard observer and $0.8 \mathrm{~cm}$ port/viewing area). Before use, the colorimeter was standardised using a white tile (mod CR-A43). Instrumental colour determinations were made on six measurements in different areas of the surface of the samples.

\section{Thiobarbituric acid reactive substances}

The evaluation of lipid stability was performed by measuring TBARS during storage following the method of Witte et al. (1970) with suitable modifications. Briefly, $10 \mathrm{~g}$ of sample were triturated with $25 \mathrm{~mL}$ of precooled $20 \%$ trichloroacetic acid (TCA) for $2 \mathrm{~min}$. The content was then quantitatively transferred into a beaker by rinsing with 25 $\mathrm{mL}$ of chilled distilled water. They were well mixed and filtered through Whatman filter paper No. 1. Three milliliters of TCA extract (filtrate) were mixed with $3 \mathrm{~mL}$ of thiobarbituric acid (TBA) reagent $(5 \mathrm{mM})$ in test tubes and placed in a dark room for $16 \mathrm{~h}$. A blank sample was made by mixing $3 \mathrm{~mL}$ of $10 \%$ TCA and $3 \mathrm{~mL}$ of $5 \mathrm{mM}$ TBA reagent. The absorbance was measured at a fixed wavelength of 532 using a UV-VIS spectrophotometer (SHIMADZU, UV spectrophotometer UV-1800, Kyoto, Japan). The TBA value was calculated as $\mathrm{mg}$ malonaldehyde per $\mathrm{kg}$ of sample by multiplying the absorbance value with a factor of 5.2.

\section{Peroxide value}

The procedure as described by Koniecko (1979) was used with slight modifications. Five $\mathrm{g}$ of sample was blended for $2 \mathrm{~min}$. with $30 \mathrm{~mL}$ chloroform in the presence of anhydrous sodium sulphate. The mixture was filtered through Whatman filter paper No.1 and $25 \mathrm{~mL}$ aliquot of the filtered chloroform extract was transferred to $250 \mathrm{~mL}$ conical flask to which $30 \mathrm{~mL}$ of glacial acetic acid and 2 $\mathrm{mL}$ of saturated potassium iodide solution were added and allowed to stand for $2 \mathrm{~min}$ with occasional shaking (swirling) after which $100 \mathrm{~mL}$ of distilled water and $2 \mathrm{~mL}$ of fresh $1 \%$ starch solution were added. Flask contents were titrated immediately against $0.1 \mathrm{~N}$ sodium thiosulphate till the end point was reached (non-aqueous layer turned to 
colourless). The PV was calculated in $\mathrm{mEq} / \mathrm{kg}$ of the sample as per the following formula.

$$
\begin{aligned}
& \mathrm{PV}(\mathrm{mEq} / \mathrm{kg} \text { sample }) \\
& =0.1 \times \mathrm{mL} 0.1 \mathrm{~N} \text { sodium thiosulphate } \\
& \quad / \text { sample weight }(\mathrm{g}) \times 100
\end{aligned}
$$

\section{Free fatty acids}

The method as described by Koniecko (1979) was followed for quantification of FFAs. For this, $5 \mathrm{~g}$ of sample was blended for $2 \mathrm{~min}$. with $30 \mathrm{~mL}$ chloroform in the presence of anhydrous sodium sulphate. The mixture was filtered through Whatman filter paper No. 1 into a $100 \mathrm{~mL}$ conical flask. About 2 or 3 drops of $0.2 \mathrm{~g} / 100 \mathrm{~mL}$ phenolphthalein indicator solution were added to the chloroform extract, which was then titrated against $0.1 \mathrm{~N}$ alcoholic potassium hydroxide to get the pink colour end point. The quantity of potassium hydroxide required for titration was recorded and calculated as follows:

\section{FFA $\%=0.1 \times \mathrm{mL} 0.1 \mathrm{~N}$ alcoholic $\mathrm{KOH} \times 0.282$ /Wt. of sample $(\mathrm{g}) \times 100$}

\section{Statistical analysis}

The whole experiment was repeated three times and each parameter was evaluated in duplicate, whereas the instrumental colour profile measurements were made in sextuplicate. The data generated were analysed statistically on SPSS V.20 (SPSS Inc., Chicago, IL, USA) software packages as per standard methods. The average values were reported along with standard error. Means between the periods of storage, between treatments and within treatments were compared by two-way analysis of variance. The statistical significance was estimated at 5\% level $(\mathrm{p}<0.05)$ and evaluated with Duncan's Multiple Range Test.

\section{RESULTS AND DISCUSSION}

\section{Changes in $\mathbf{p H}$ and water activity $\left(\mathrm{a}_{\mathrm{w}}\right)$}

The $\mathrm{pH}$ of the pork frankfurters varied $(\mathrm{p}<0.05)$ among all treatments and storage periods (Table 1). The $\mathrm{pH}$ differences amongst treatments on day 1 of storage might be due to variation of $\mathrm{pH}$ of the added phyto-extracts viz. GTE 4.99, GSE 4.27, FSE 5.8, ACE 4.43, and SBT 3.13. Over the 20 day display period the $\mathrm{pH}$ values of SBT and ACE did not vary greatly. In general, $\mathrm{pH}$ values decreased throughout the storage up to day 10 . The variation in $\mathrm{pH}$ can be influenced by growth of lactic acid bacteria which in turn leads to production of lactic acid and deamination of proteins (Cayré et al., 2003). Various studies depicted that the final increase in the $\mathrm{pH}$ might be due to the low carbohydrate content, formation of $\mathrm{N}$ non-protein compounds and basic ammonium ions coupled with buffering actions of meat protein (Wardlaw et al., 1973).

Water activity $\left(\mathrm{a}_{\mathrm{w}}\right)$ plays a great role in meat preservation, because it has well proven correlation with the potential growth and metabolic activity of microorganisms. Its measurement has been a valuable tool for predicting the microbial stability (and safety) of meat and meat products (Fernández-Salguero et al., 1993).

In present study, water activity was comparable amongst

\begin{tabular}{|c|c|c|c|c|c|}
\hline \multirow{2}{*}{ Parameters } & \multicolumn{5}{|c|}{ Storage periods $(\mathrm{d})$} \\
\hline & 1 & 5 & 10 & 15 & 20 \\
\hline \multicolumn{6}{|l|}{$\mathrm{pH}$} \\
\hline Control & $6.40 \pm 0.0^{\mathrm{Dc}}$ & $6.30 \pm 0.02^{\mathrm{Db}}$ & $6.25 \pm 0.04^{\mathrm{Aba}}$ & $6.29 \pm 0.02^{\mathrm{DEb}}$ & $6.31 \pm 0.01^{\mathrm{Db}}$ \\
\hline $\mathrm{T}_{1}(0.30 \% \mathrm{SBT})$ & $6.33 \pm 0.08^{\mathrm{Bd}}$ & $6.26 \pm 0.03^{\mathrm{ABa}}$ & $6.28 \pm 0.01^{\mathrm{Cb}}$ & $6.31 \pm 0.02^{\mathrm{Ec}}$ & $6.29 \pm 0.02^{\mathrm{Cb}}$ \\
\hline $\mathrm{T}_{2}(0.10 \% \mathrm{GSE})$ & $6.36 \pm 0.06^{\mathrm{Cb}}$ & $6.28 \pm 0.02^{\mathrm{CDa}}$ & $6.27 \pm 0.01^{\mathrm{BCa}}$ & $6.29 \pm 0.02^{\mathrm{CDa}}$ & $6.29 \pm 0.01^{\mathrm{Ca}}$ \\
\hline $\mathrm{T}_{3}(0.03 \% \mathrm{GTE})$ & $6.30 \pm 0.06^{\mathrm{Ab}}$ & $6.23 \pm 0.04^{\mathrm{ABa}}$ & $6.22 \pm 0.04^{\mathrm{Aa}}$ & $6.22 \pm 0.01^{\mathrm{Aa}}$ & $6.23 \pm 0.01^{\mathrm{Aa}}$ \\
\hline $\mathrm{T}_{4}(0.12 \%$ FSE $)$ & $6.36 \pm 0.05^{\mathrm{Cb}}$ & $6.27 \pm 0.07^{\mathrm{CDa}}$ & $6.24 \pm 0.01^{\mathrm{Aba}}$ & $6.24 \pm 0.04^{\mathrm{Ba}}$ & $6.25 \pm 0.02^{\mathrm{Ba}}$ \\
\hline $\mathrm{T}_{5}(0.10 \%$ ACE $)$ & $6.29 \pm 0.06^{\mathrm{Ad}}$ & $6.22 \pm 0.05^{\mathrm{Aa}}$ & $6.24 \pm 0.02^{\mathrm{Ab}}$ & $6.27 \pm 0.01^{\mathrm{Cc}}$ & $6.25 \pm 0.02^{\mathrm{Bb}}$ \\
\hline \multicolumn{6}{|l|}{$\mathrm{a}_{\mathrm{w}}$} \\
\hline Control & $0.990 \pm 0.01^{\mathrm{Ae}}$ & $0.962 \pm 0.07^{\mathrm{Ad}}$ & $0.942 \pm 0.03^{\mathrm{Ac}}$ & $0.842 \pm 0.01^{\mathrm{Ab}}$ & $0.806 \pm 0.01^{\mathrm{Aa}}$ \\
\hline $\mathrm{T}_{1}(0.30 \% \mathrm{SBT})$ & $0.993 \pm 0.01^{\mathrm{Be}}$ & $0.990 \pm 0.01^{\mathrm{Cd}}$ & $0.975 \pm 0.01^{\mathrm{Dc}}$ & $0.913 \pm 0.01^{\mathrm{Fb}}$ & $0.895 \pm 0.02^{\mathrm{Fa}}$ \\
\hline $\mathrm{T}_{2}(0.10 \% \mathrm{GSE})$ & $0.990 \pm 0.01^{\mathrm{Ae}}$ & $0.985 \pm 0.02^{\mathrm{Cd}}$ & $0.968 \pm 0.01^{\mathrm{Cc}}$ & $0.893 \pm 0.02^{\mathrm{Db}}$ & $0.874 \pm 0.01^{\mathrm{Da}}$ \\
\hline $\mathrm{T}_{3}(0.03 \% \mathrm{GTE})$ & $0.991 \pm 0.01^{\mathrm{ABe}}$ & $0.974 \pm 0.01^{\mathrm{Ad}}$ & $0.959 \pm 0.02^{\mathrm{Bc}}$ & $0.862 \pm 0.01^{\mathrm{Bb}}$ & $0.853 \pm 0.02^{\mathrm{Ba}}$ \\
\hline $\mathrm{T}_{4}(0.12 \% \mathrm{FSE})$ & $0.992 \pm 0.01^{\mathrm{ABe}}$ & $0.981 \pm 0.01^{\mathrm{BCd}}$ & $0.961 \pm 0.01^{\mathrm{Bc}}$ & $0.883 \pm 0.01^{\mathrm{Cb}}$ & $0.864 \pm 0.01^{\mathrm{Ca}}$ \\
\hline $\mathrm{T}_{5}(0.10 \% \mathrm{ACE})$ & $0.991 \pm 0.01^{\mathrm{ABe}}$ & $0.987 \pm 0.01^{\mathrm{Cd}}$ & $0.971 \pm 0.02^{\mathrm{CDc}}$ & $0.905 \pm 0.03^{\mathrm{Eb}}$ & $0.889 \pm 0.01^{\mathrm{Ea}}$ \\
\hline
\end{tabular}
treatments on day 1 but varied $(\mathrm{p}<0.05)$ with progress of

Table 1. Effect of added phyto-extracts on $\mathrm{pH}$ and water activity $\left(\mathrm{a}_{\mathrm{w}}\right)$ of pork frankfurters during refrigerated storage

Control, without any extracts; SBT, sea buckthorn seed extract; GSE, grape seed extract; GTE, green tea extract; FSE, fenugreek seed extract; ACE, Acacia catechu extract.

Values are mean \pm standard error $(n=6)$.

${ }^{a-d}$ Means with different letters in the same row are significantly different $(\mathrm{p}<0.05)$.

${ }^{A-D}$ Means with different letters in the same column are significantly different $(\mathrm{p}<0.05)$. 
storage period (Table 1). The $\mathrm{a}_{\mathrm{w}}$ values of pork frankfurters were affected $(\mathrm{p}<0.05)$ by the addition of phyto-extracts during storage showing greater $a_{w}$ values in frankfurters incorporated with SBT and ACE extract than GSE, GTE, and CONTROL groups. Similar trend continued throughout the storage period. On last day of storage, $\mathrm{a}_{\mathrm{w}}$ was measured in the order $\mathrm{SBT}>\mathrm{ACE}>\mathrm{GSE}>\mathrm{GTE}>\mathrm{FSE}>\mathrm{CONTROL}$. The observed $\mathrm{a}_{\mathrm{w}}$ decrease is largely due to the water loss and has a direct correlation with moisture content $(r=0.93, \mathrm{p}<0.01)$. Decrease in $a_{w}$ might be due to increased microbial load of the treated as well as control samples. These findings were in accordance with the observation recorded for analogous meat products (Mc Carthy et al., 2001).

\section{Thiobarbituric acid reactive substances}

Figure 1 shows the effect of different phyto-extracts on TBARS values of pork frankfurters during 20 days refrigerated storage. The analysis of variance for the TBARS data indicated that the TBARS values varied $(\mathrm{p}<0.05)$ amongst the control sample and phyto-extracts treated products throughout storage. The initial difference in oxidation levels can be explained as a consequence of the variability in antioxidant activity of the added phytoextracts in the meat systems. Initial (day 1) TBARS values for SBT and FSE treated samples recorded lower $(\mathrm{p}<0.05)$ than control. This observation suggests that these extracts retarded lipid oxidation during the cooking. In general, TBARS values increased with increasing storage period. TBARS values of all treatments were considerably lower $(\mathrm{p}<0.05)$ than control throughout storage period, thus indicating high shielding properties of added phyto-extracts against lipid oxidation. Up to day 5 of storage the highest values of TBARS were found in control and GTE but onward increasing $(\mathrm{p}<0.05)$ fast in control, which indicates GTE had antioxidant properties during pork frankfurters storage. The GTE was ranked as the least effective whereas SBT was the most effective phyto-extract in pork frankfurters. Furthermore, it is interesting to point out that GSE was more potent antioxidant than GTE throughout storage which might be due to differences in total phenolic compounds. It is attributed that antioxidant activity determined in GSE was higher than GTE due to their phenolic contents. Our observation concerning the relative effect of the antioxidants in green tea versus GSE, for instance from the proanthocyanidins, agrees with an earlier study (Lorenzo et al., 2013). The efficiency of the phytoextract in inhibiting lipid oxidation throughout refrigerated storage was in the following order: $\mathrm{SBT}>\mathrm{ACE}>\mathrm{GSE}$ $>$ FSE $>$ GTE.

\section{Peroxide value}

Peroxide value is indicative of the amount of hydroperoxides formed as primary oxidation products. Hydroperoxide initiate autoxidation of lipid by attacking on the double bond in fatty acids and subsequently produce carbonyl compounds. These peroxides are very reactive and may decrease during the storage of foods of rich in fat (Juntachote et al., 2007). Therefore, it seemed reasonable to determine the contents of peroxides in meat samples to clarify the extent of oxidation.

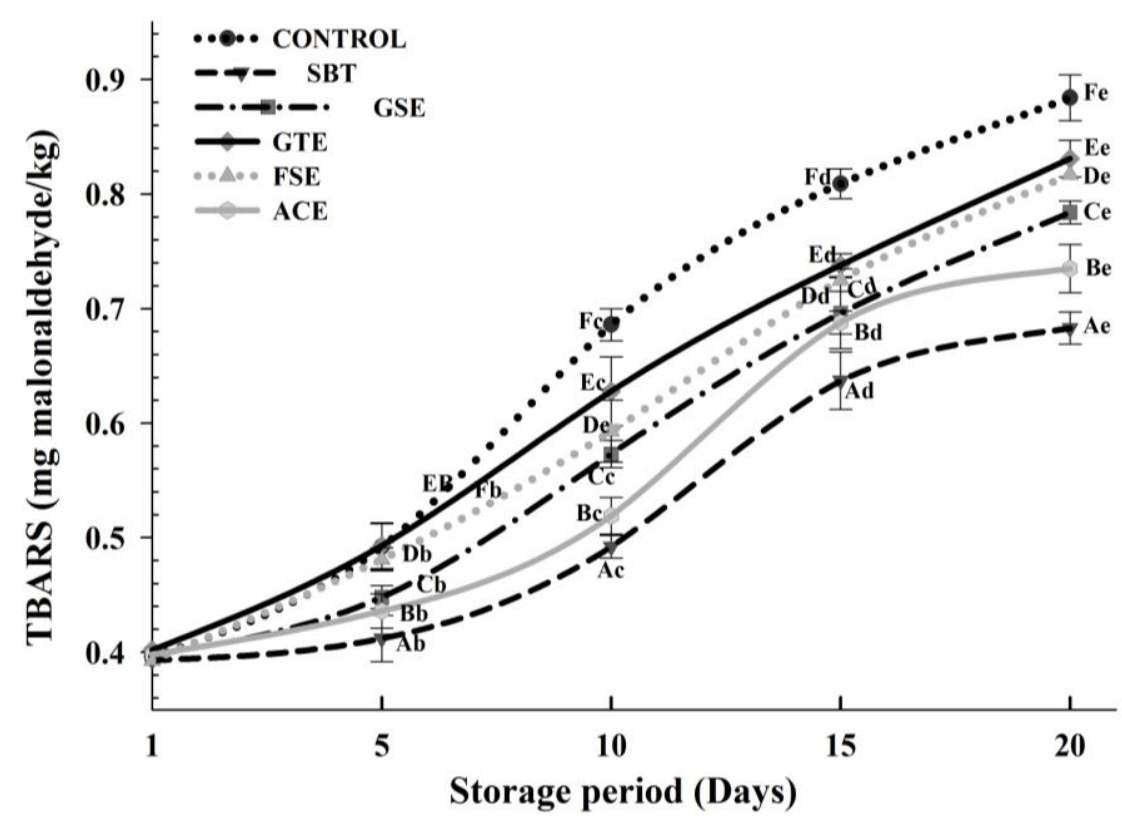

Figure 1. Effect of added phyto-extracts on thiobarbituric acid reactive substances (TBARS) of pork frankfurters during refrigerated storage. Samples were treated as follows: CONTROL, without any extracts; SBT, 0.30\% sea buckthorn seed extract; GSE, 0.10\% grape seed extract; GTE, $0.03 \%$ green tea extract; FSE, $0.12 \%$ fenugreek seed extract; ACE, $0.10 \%$ Acacia catechu extract. Bar represents the standard error $(n=6)$. 
Change in PV of phyto-extract treated pork frankfurters during storage is shown in Figure 2. The initial PV of the control was $0.89 \mathrm{mEq} / \mathrm{kg}$ and increased to $1.36 \mathrm{mEq} / \mathrm{kg}$ after 10 days of storage, which was higher $(\mathrm{p}<0.05)$ than other treatments. The initial PVs of pork frankfurters with SBT $(0.56 \mathrm{mEq} / \mathrm{kg})$, GSE (0.63 $\mathrm{mEq} / \mathrm{kg})$, GTE $(0.65$ $\mathrm{mEq} / \mathrm{kg}), \mathrm{FSE}(0.64 \mathrm{mEq} / \mathrm{kg})$ and ACE $(0.61 \mathrm{mEq} / \mathrm{kg})$ were lower $(\mathrm{p}<0.05)$ than control. Oxidation in the control was more intense compared to the treated samples; maximum values for PV were reached on day 10, after which a decline was observed, indicating that after the induction period, the decomposition rate of the hydroperoxides was faster than the production rate. At that point of storage the rate of hydroperoxides decomposition was higher than the rate of formation (Barbut et al., 1985).

In agreement with the data on TBARS, the best antioxidative effect $(\mathrm{p}<0.05)$ was obtained by the SBT and $\mathrm{ACE}$, for which the values of PV were lowest at the end of storage period (day 20) than those obtained as early as day 5 in the controls, probably because their high polyphenol constituents function as antioxidants by terminating free radical chain-type reactions (Juntachote et al., 2006). Furthermore, samples containing GSE and FSE had lower PV concentrations than those containing the GTE at the end of storage period (Figure 2).

\section{Free fatty acid}

The primary oxidation products continually produce several secondary oxidation products, including aldehydes, ketones and FFAs etc., which are generated by autoxidation, enzyme oxidation, and photosensitized oxidation (Frankel, 1991). In particular, the formation of FFA is associated with the decomposition of lipids hydrolysed by endogenous lipolytic enzymes (Juntachote et al., 2006). The amounts of FFAs are actually a value for lipolysis which can be regarded as a measurement of decreased oxidative stability of the meat and meat products.

As expected, the FFA contents increased $(p<0.05)$ during storage irrespective of the treatment (Figure 3). The largest increase was observed in control. An increase in FFA values is due to lipase action in meat products during storage which are justified by previous studies on pork sausages (Fernández and Rodríguez, 1991).

Throughout storage period of 20 days, the FFA level in pork frankfurters containing SBT and ACE followed a lower $(\mathrm{p}<0.05)$ trend than others including control. Starting from $0.115 \%$ (SBT), $0.125 \%$ (ACE), $0.123 \%$ (GSE), $0.132 \%$ (GTE), $0.128 \%$ (FSE), and $0.129 \%$ (control), increased up to $0.213 \%$ (SBT), $0.259 \%$ (ACE), $0.287 \%$ (GSE), $\quad 0.315 \%$ (GTE), $0.307 \%$ (FSE), and $0.431 \%$ (control), respectively at the end of storage period. The FFA levels observed in the present study are similar to the values reported by Reddy et al. (2013) for restructured mutton slices.

\section{Instrumental colour profile}

Pork frankfurters exhibited different colour characteristics depending on the addition of phyto-extracts

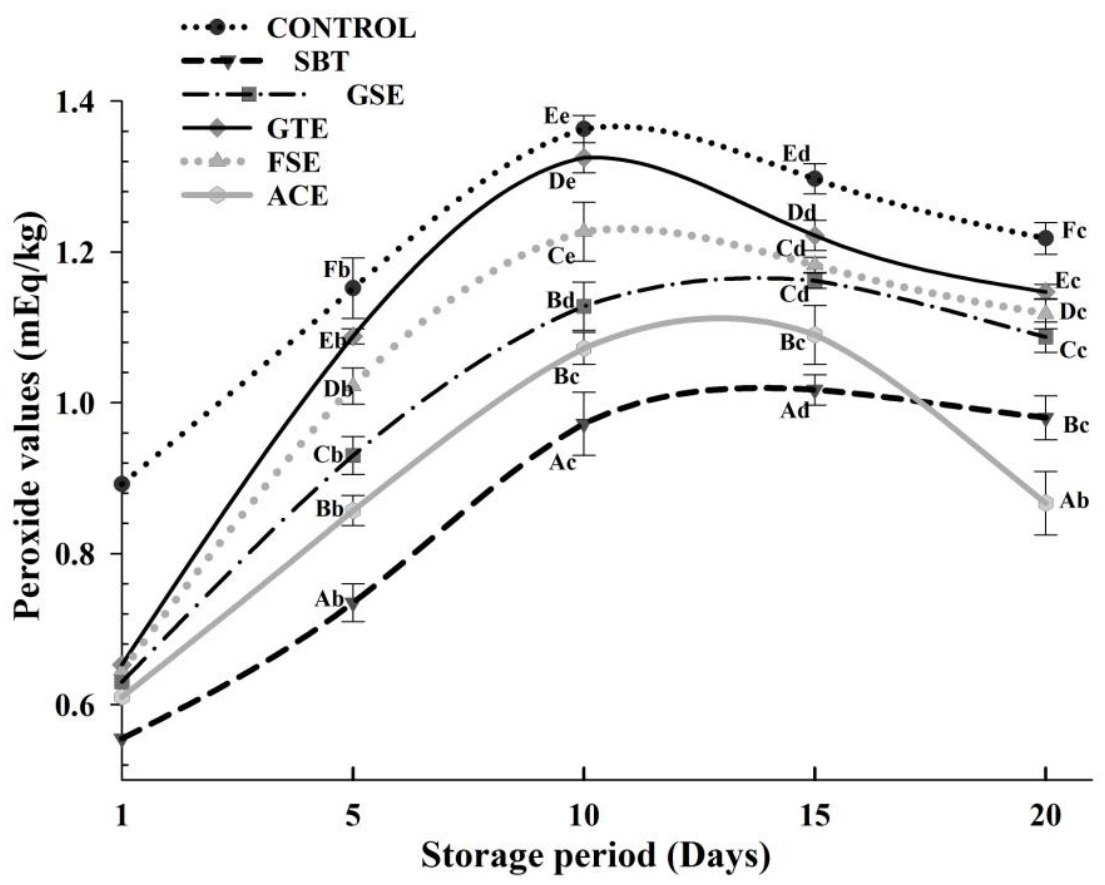

Figure 2. Effect of added phyto-extracts on peroxide value (PV) of pork frankfurters during refrigerated storage. Samples were treated as follows: CONTROL, without any extracts; SBT, 0.30\% sea buckthorn seed extract; GSE, $0.10 \%$ grape seed extract; GTE, $0.03 \%$ green tea extract; FSE, $0.12 \%$ fenugreek seed extract; ACE, 0.10\%. Acacia catechu extract. Bar represents the standard error $(n=6)$. 


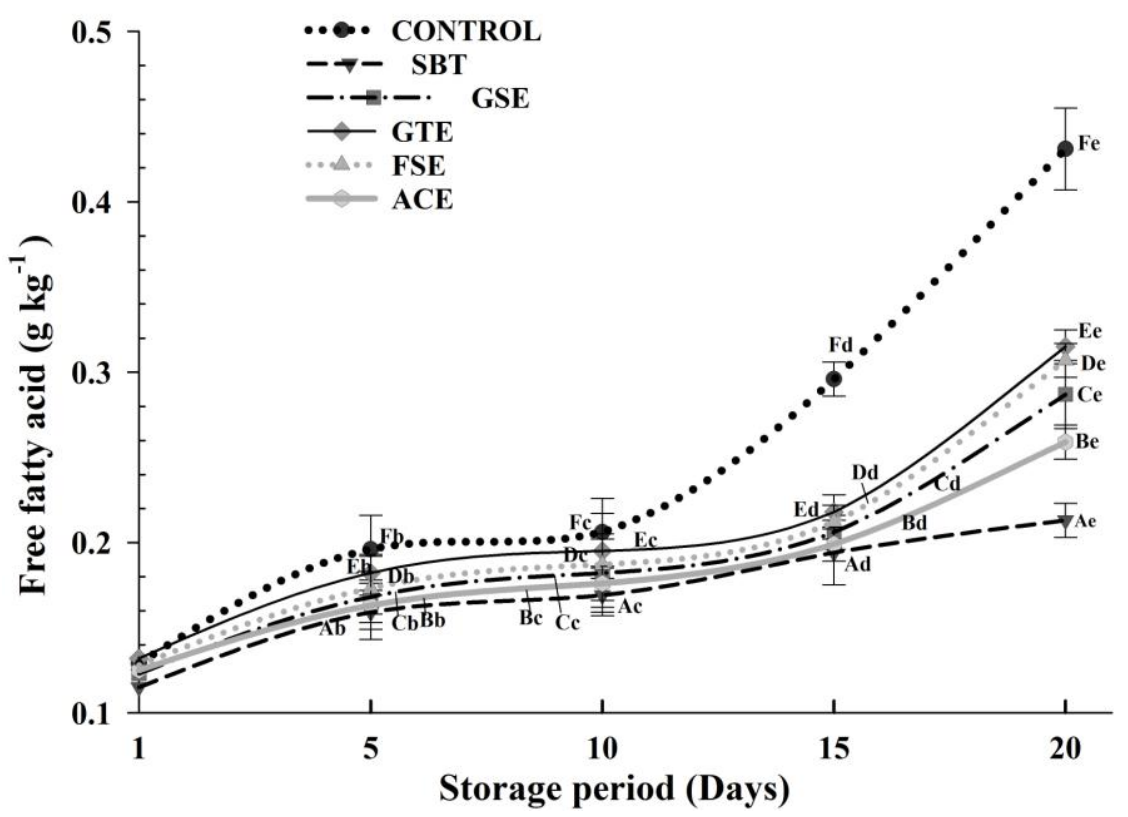

Figure 3. Effect of added phyto-extracts on free fatty acids (FFA) of pork frankfurters during refrigerated storage. Samples were treated as follows: CONTROL, without any extracts; SBT, 0.30\% sea buckthorn seed extract; GSE, 0.10\% grape seed extract; GTE, 0.03\% green tea extract; FSE, $0.12 \%$ fenugreek seed extract; ACE, 0.10\% Acacia catechu extract. Bar represents the standard error $(\mathrm{n}=6)$.

(Table 2). Lightness $\left(L^{*}\right)$ values were found equal in all the treated samples on day 1 . Thereafter, throughout storage $L^{*}$ values were lower $(\mathrm{p}<0.05)$ for control as compared to all phyto-extract treated samples. On day 20, $L^{*}$ values reported highest in SBT, ACE, GSE, and FSE extracts followed by GTE. This might be due to the higher ability of the SBT, ACE, GSE, and FSE to maintain the colour of the product by retarding the oxidation reaction. At the end of storage period (day 20), control showed lowest $L^{*}$ values. These colour changes could be linked to oxidation phenomena and several factors as the packing method, the browning reaction, the drying of products and the presence of antioxidants. These observations are in agreement with findings in different meat products (Kim et al., 2013).

Overall there was an increase in $a^{*}$ values followed by decrease during storage which was faster in control and GTE as compared to others (Table 2). After 15 days of storage, a slight decrease in $a^{*}$ values was observed in all samples; this decrease in redness may be attributed to the oxidation of nitrosyl-myoglobin (Sachindra and Mahendrakar, 2010). From Table 2, it is clear that $a^{*}$ values of the control samples decreased $(\mathrm{p}<0.05)$ from 8.72 on day 10 to 7.33 on day 20 , while the values of SBT samples reached 13.85 on the 20th day. At the end of storage (day 20) $a^{*}$ values of the control samples were lower $(\mathrm{p}<0.05)$ than day 1 , and lower than that of treated products. Several authors have studied the effect of different antioxidants on the colour of meat and meat products and reported that lipid oxidation resulted in decreased redness (Kim et al., 2013). It is reasonable that the colour changes in cooked products are caused by oxidative reactions since the addition of substances with proven antioxidant activity inhibit to some extent the discoloration of frankfurters and other meat products (Sebranek et al., 2005). Yellowness ( $b^{*}$ values) increased over time, and slight differences were exhibited among treated products. In general the control showed highest $b^{*}$ values, except on day 5 as compared to GTE. Among the added phyto-extracts, GTE showed higher $(p<0.05)$ yellowness values throughout the storage period. The increased yellowness at day 1 is likely to be partly caused by lower antioxidative efficiency of the GTE during processing. In addition, catechins are key ingredients in GTEs and heating will cause the colour to be less green and deeper yellow (Sebranek et al., 2005).

\section{CONCLUSION}

Results demonstrate that incorporation of SBT seed extracts and ACEs had positive effects on oxidative and colour stability in pork frankfurters during refrigerated storage for 20 days. The pork frankfurters made with addition of $0.30 \%$ SBT and $0.10 \%$ ACE had lowest TBARS value, FFA, and PVs. The efficiency of the phyto-extract in inhibiting lipid oxidation throughout refrigerated storage was in the following order: $\mathrm{SBT}>\mathrm{ACE}>\mathrm{GSE}>\mathrm{FSE}>\mathrm{GTE}$. The addition of antioxidants improved quality traits of pork frankfurters by stabilizing their colour attributes and physico-chemical qualities during refrigerated storage. Consequently, the used phyto-extracts are good functional supplements to processed meat products, retarding the 
Table 2. Effect of added phyto-extracts on colour attributes of pork frankfurters during refrigerated storage

\begin{tabular}{|c|c|c|c|c|c|}
\hline \multirow{2}{*}{ Parameters } & \multicolumn{5}{|c|}{ Storage periods $(\mathrm{d})$} \\
\hline & 1 & 5 & 10 & 15 & 20 \\
\hline \multicolumn{6}{|l|}{$L^{*}$} \\
\hline Control & $58.20 \pm 0.35^{\mathrm{c}}$ & $56.40 \pm 0.55^{\mathrm{Ab}}$ & $56.46 \pm 0.13^{\mathrm{Ab}}$ & $55.86 \pm 0.17^{\mathrm{Ab}}$ & $54.65 \pm 0.12^{\mathrm{Aa}}$ \\
\hline $\mathrm{T}_{1}(0.30 \% \mathrm{SBT})$ & $58.13 \pm 0.33^{\mathrm{a}}$ & $58.04 \pm 0.21^{\mathrm{Ba}}$ & $57.94 \pm 0.38^{\mathrm{Ba}}$ & $57.89 \pm 0.29^{\mathrm{Ba}}$ & $57.86 \pm 0.42^{\mathrm{Ca}}$ \\
\hline $\mathrm{T}_{2}(0.10 \% \mathrm{GSE})$ & $58.09 \pm 0.25$ & $58.03 \pm 0.35^{\mathrm{B}}$ & $57.88 \pm 0.54^{\mathrm{B}}$ & $57.74 \pm 0.22^{\mathrm{B}}$ & $57.66 \pm 0.15^{\mathrm{C}}$ \\
\hline $\mathrm{T}_{3}(0.03 \%$ GTE $)$ & $58.11 \pm 0.38^{\mathrm{b}}$ & $57.98 \pm 0.24^{\mathrm{Bb}}$ & $57.78 \pm 0.49^{\mathrm{Bb}}$ & $56.36 \pm 0.44^{\mathrm{Aa}}$ & $55.79 \pm 0.66^{\mathrm{Ba}}$ \\
\hline $\mathrm{T}_{4}(0.12 \%$ FSE $)$ & $58.06 \pm 0.32$ & $58.05 \pm 0.02^{\mathrm{B}}$ & $57.88 \pm 0.44^{\mathrm{B}}$ & $57.80 \pm 0.12^{\mathrm{B}}$ & $57.54 \pm 0.13^{\mathrm{C}}$ \\
\hline $\mathrm{T}_{5}(0.10 \% \mathrm{ACE})$ & $58.13 \pm 0.31$ & $58.10 \pm 0.39^{\mathrm{B}}$ & $57.91 \pm 0.31^{\mathrm{B}}$ & $57.81 \pm 0.05^{\mathrm{B}}$ & $57.79 \pm 0.11^{\mathrm{C}}$ \\
\hline \multicolumn{6}{|l|}{$a^{*}$} \\
\hline Control & $9.15 \pm 0.10^{\mathrm{Ab}}$ & $11.83 \pm 0.40^{\mathrm{Ac}}$ & $8.72 \pm 0.49^{\mathrm{Ab}}$ & $8.15 \pm 0.37^{\mathrm{Aab}}$ & $7.33 \pm 0.49^{\mathrm{Aa}}$ \\
\hline $\mathrm{T}_{1}(0.30 \% \mathrm{SBT})$ & $10.19 \pm 0.05^{\mathrm{Ba}}$ & $12.38 \pm 0.46^{\mathrm{Ab}}$ & $13.14 \pm 0.28^{\mathrm{Bbc}}$ & $14.09 \pm 0.46^{\mathrm{Ec}}$ & $13.85 \pm 0.30^{\mathrm{Cc}}$ \\
\hline $\mathrm{T}_{2}(0.10 \% \mathrm{GSE})$ & $10.16 \pm 0.05^{\mathrm{Ba}}$ & $12.23 \pm 0.63^{\mathrm{Ab}}$ & $13.03 \pm 0.61^{\mathrm{Bc}}$ & $11.24 \pm 0.36^{\mathrm{Cab}}$ & $11.04 \pm 0.43^{\mathrm{Bab}}$ \\
\hline $\mathrm{T}_{3}(0.03 \%$ GTE $)$ & $10.07 \pm 0.07^{\mathrm{Bb}}$ & $12.07 \pm 0.46^{\mathrm{Ac}}$ & $12.17 \pm 0.48^{\mathrm{Bc}}$ & $10.01 \pm 0.01^{\mathrm{Bb}}$ & $7.93 \pm 0.33^{\mathrm{Aa}}$ \\
\hline $\mathrm{T}_{4}(0.12 \% \mathrm{FSE})$ & $10.17 \pm 0.03^{\mathrm{Ba}}$ & $12.19 \pm 0.45^{\mathrm{Ab}}$ & $13.10 \pm 0.32^{\mathrm{Bc}}$ & $12.59 \pm 0.20^{\mathrm{Db}}$ & $10.08 \pm 0.05^{\mathrm{Ba}}$ \\
\hline $\mathrm{T}_{5}(0.10 \% \mathrm{ACE})$ & $10.14 \pm 0.02^{\mathrm{Ba}}$ & $12.33 \pm 0.33^{\mathrm{Ab}}$ & $13.04 \pm 0.26^{\mathrm{Bbc}}$ & $14.00 \pm 0.63^{\mathrm{Ec}}$ & $13.05 \pm 0.69^{\mathrm{Cbc}}$ \\
\hline \multicolumn{6}{|l|}{$b^{*}$} \\
\hline Control & $10.08 \pm 0.04^{\mathrm{Ea}}$ & $10.26 \pm 0.03^{\mathrm{Bab}}$ & $10.52 \pm 0.02^{\mathrm{Db}}$ & $10.63 \pm 0.02^{\mathrm{Ebc}}$ & $10.96 \pm 0.02^{\mathrm{Dc}}$ \\
\hline $\mathrm{T}_{1}(0.30 \% \mathrm{SBT})$ & $9.24 \pm 0.02^{\mathrm{Aa}}$ & $9.34 \pm 0.01^{\text {Aab }}$ & $9.39 \pm 0.01^{\mathrm{Aab}}$ & $9.42 \pm 0.02^{\mathrm{Bab}}$ & $9.58 \pm 0.05^{\mathrm{Ab}}$ \\
\hline $\mathrm{T}_{2}(0.10 \% \mathrm{GSE})$ & $9.26 \pm 0.01^{\mathrm{Ba}}$ & $9.36 \pm 0.01^{\mathrm{Aab}}$ & $9.46 \pm 0.03^{\mathrm{Bb}}$ & $9.93 \pm 0.01^{\mathrm{Cbc}}$ & $9.95 \pm 0.03^{\mathrm{Bc}}$ \\
\hline $\mathrm{T}_{3}(0.03 \%$ GTE $)$ & $9.54 \pm 0.02^{\mathrm{Da}}$ & $10.29 \pm 0.02^{\mathrm{Bb}}$ & $10.43 \pm 0.02^{\mathrm{Cc}}$ & $10.55 \pm 0.03^{\mathrm{Dd}}$ & $10.61 \pm 0.05^{\mathrm{Ce}}$ \\
\hline $\mathrm{T}_{4}(0.12 \% \mathrm{FSE})$ & $9.29 \pm 0.01^{\mathrm{Ca}}$ & $9.32 \pm 0.03^{\mathrm{Aab}}$ & $9.44 \pm 0.01^{\mathrm{Bab}}$ & $9.56 \pm 0.01^{\mathrm{Bb}}$ & $9.96 \pm 0.01^{\mathrm{Bc}}$ \\
\hline $\mathrm{T}_{5}(0.10 \%$ ACE $)$ & $9.25 \pm 0.01^{\mathrm{ABa}}$ & $9.30 \pm 0.01^{\text {Aab }}$ & $9.32 \pm 0.03^{\mathrm{Aab}}$ & $9.33 \pm 0.01^{\mathrm{Ab}}$ & $9.59 \pm 0.01^{\mathrm{Ac}}$ \\
\hline
\end{tabular}

Control, without any extracts; SBT, sea buckthorn seed extract; GSE, grape seed extract; GTE, green tea extract; FSE, fenugreek seed extract; ACE, Acacia catechu extract.

Values are mean \pm standard error $(n=6)$.

${ }^{a-d}$ Means with different letters in the same row are significantly different $(\mathrm{p}<0.05)$.

${ }^{A-E}$ Means with different letters in the same column are significantly different $(\mathrm{p}<0.05)$.

oxidation of fatty acids as well as enriching the meat products with plant-derived beneficial polyphenols. Future studies concerning the effect of listed phyto-extracts on protein oxidation would be of interest and also meat industries may consider exploring these phyto-extracts for developing functional meat products with improved shelf life and stability.

\section{ACKNOWLEDGMENTS}

Authors appreciate Department of Food and Environmental Sciences, University of Helsinki, Helsinki, Finland for providing laboratory facilities. Authors would like special thanks to Mr. Pekka Kahila, Meat pilot plant for his technical assistance in the development of products. Authors acknowledge the financial support provided by the Centre for International Mobility (CIMO), Finland under Doctoral Finnish Government Scholarship Pool Programme and University Grants Commission, New Delhi, India.

\section{REFERENCES}

Armenteros, M., D. Morcuende, S. Ventanas, and M. Estévez. 2013. Application of natural antioxidants from Strawberry tree
(Arbutus Unedo L.) and Dog rose (Rosa Canina L.) to frankfurters subjected to refrigerated storage. J. Integr. Agric. 12:1972-1981.

Bal, L. M., V. Meda, S. N. Naik, and S. Satya. 2011. Sea buckthorn berries: a potential source of valuable nutrients for nutraceuticals and cosmoceuticals. Food Res. Int. 44:17181727.

Barbut, S., D. B. Josephson, and A. J. Maurer. 1985. Antioxidant properties of Rosemary oleoresin in Turkey sausage. J. Food Sci. 50:1356-1359.

Cavenaghi-Altemio, A. D., L. B. Alcade, and G. G. Fonseca. 2013. Low-fat frankfurters from protein concentrates of tilapia viscera and mechanically separated tilapia meat. Food Sci. Nutr. 1:445-451.

Cayré, M. E., G. Vignolo, and O. Garro. 2003. Modeling lactic acid bacteria growth in vacuum-packaged cooked meat emulsions stored at three temperatures. Food Microbiol. 20: 561-566.

Devatkal, S. K., P. R. Thorat, M. Manjunatha, and R. K. Anurag. 2012. Comparative antioxidant effect of aqueous extracts of curry leaves, fenugreek leaves and butylated hydroxytoluene in raw chicken patties. J. Food Sci. Technol. 49:781-785.

Fernández, M. C. D. and J. M. Z. Rodríguez. 1991. Lipolytic and oxidative changes in 'chorizo' during ripening. Meat Sci. 29: 99-107.

Fernández-López, J., L. Sevilla, E. Sayas-Barberá, C. Navarro, F. 
Marín, and J. A. Pérez-Alvarez. 2003. Evaluation of the antioxidant potential of Hyssop (Hyssopus officinalis L.) and Rosemary (Rosmarinus officinalis L.) extracts in cooked pork meat. J. Food Sci. 68:660-664.

Fernández-Salguero, J., R. Gómez, and M. A. Carmona. 1993. Water activity in selected high-moisture foods. J. Food Compost. Anal. 6:364-369.

Frankel, E. N. 1991. Review - Recent advances in lipid oxidation. J. Sci. Food Agric. 54:495-511.

Juntachote, T., E. Berghofer, S. Siebenhandl, and F. Bauer. 2006. The antioxidative properties of holy basil and galangal in cooked ground pork. Meat Sci. 72:446-456.

Juntachote, T., E. Berghofer, S. Siebenhandl, and F. Bauer. 2007. The effect of dried galangal powder and its ethanolic extracts on oxidative stability in cooked ground pork. LWT - Food Sci. Technol. 40:324-330.

Kim, E., D. Coelho, and F. Blachier. 2013. Review of the association between meat consumption and risk of colorectal cancer. Nutr. Res. 33:983-994.

Koniecko, E. S. 1979. Handbook for Meat Chemists. Avery Publishing Group Inc., Wayne, NJ, USA. pp. 53-55.

Lau, D. W. and A. J. King. 2003. Pre- and post-mortem use of grape seed extract in dark poultry meat to inhibit development of thiobarbituric acid reactive substances. J. Agric. Food Chem. 51:1602-1607.

Li, T. S. C. and W. R. Schroeder. 1996. Sea buckthorn (Hippophae rhamnoides L.): A multipurpose plant. Hort. Technol. 6:370380.

Li, X., C. Liu, L. Yang, and R. Chen. 2011. Phenolic compounds from the aqueous extract of Acacia catechu. J. Asian Nat. Prod. Res. 13:826-830.

Lorenzo, J. M., R. M. González-Rodríguez, M. Sánchez, I. R. Amado, and D. Franco. 2013. Effects of natural (Grape seed and Chestnut extract) and synthetic antioxidants (Buthylatedhydroxytoluene, BHT) on the physical, chemical, microbiological and sensory characteristics of dry cured sausage "chorizo". Food Res. Int. 54:611-620.

Mc Carthy, T. L., J. P. Kerry, J. F. Kerry, P. B. Lynch, and D. J. Buckley. 2001. Assessment of the antioxidant potential of natural food and plant extracts in fresh and previously frozen pork patties. Meat Sci. 57:177-184.
Michel, T., E. Destandau, G. Le Floch, M. E. Lucchesi, and C. Elfakir. 2012. Antimicrobial, antioxidant and phytochemical investigations of sea buckthorn (Hippophaë rhamnoides L.) leaf, stem, root and seed. Food Chem. 131:754-760.

Nissen, L. R., D. V. Byrne, G. Bertelsen, and L. H. Skibsted. 2004. The antioxidative activity of plant extracts in cooked pork patties as evaluated by descriptive sensory profiling and chemical analysis. Meat Sci. 68:485-495.

Nutan, M. Modi, C. S. Dezzutti, S. Kulshreshtha, A. K. S. Rawat, S. K. Srivastava, S. Malhotra, A. Verma, U. Ranga, and S. K. Gupta. 2013. Extracts from Acacia catechu suppress HIV-1 replication by inhibiting the activities of the viral protease and tat. Virol. J. 10:309.

Ozvural, E. B. and H. Vural. 2011. Grape seed flour is a viable ingredient to improve the nutritional profile and reduce lipid oxidation of frankfurters. Meat Sci. 88:179-183.

Papuc, C., V. Nicorescu, N. C. Durdun, D. C. Crivineanu, and G. V. Goran. 2009. The protective effect of sea buckthorn alcoholic extract upon proteins and lipids from refrigerated beef and pork. Vet. Med. 55:94-100.

Reddy, G. V., A. R. Sen, P. N. Nair, K. S. Reddy, K. K. Reddy, and N. Kondaiah. 2013. Effects of grape seed extract on the oxidative and microbial stability of restructured mutton slices. Meat Sci. 95:288-294.

Sachindra, N. M. and N. S. Mahendrakar. 2010. Stability of carotenoids recovered from shrimp waste and their use as colorant in fish sausage. J. Food Sci. Technol. 47:77-83.

Salejda, A. M., G. Krasnowska, and U. Tril. 2011. Attempt to utilize antioxidant properties of green tea extract in the production of model meat products. Zywnosc-Nauka Technol. Jakosc. 18:107-118.

Sebranek, J. G., V. J. H. Sewalt, K. L. Robbins, and T. A. Houser. 2005. Comparison of a natural Rosemary extract and BHA/BHT for relative antioxidant effectiveness in pork sausage. Meat Sci. 69:289-296.

Wardlaw, F., G. Skelley, M. Johnson, and J. Acton. 1973. Changes in meat components during fermentation, heat processing and drying of a summer sausage. J. Food Sci. 38:1228-1231.

Witte, V. C., G. F. Krause, and M. E. Bailey. 1970. A new extraction method for determining 2-thiobarbituric acid values of pork and beef during storage. J. Food Sci. 35:582-585. 